\title{
Risk factors for the onset of prostatic cancer: age, location, and behavioral correlates
}

This article was published in the following Dove Press journal:

Clinical Epidemiology

4 January 2012

Number of times this article has been viewed

\author{
Michael F Leitzmann' \\ Sabine Rohrmann ${ }^{2}$ \\ 'Department of Epidemiology and \\ Preventive Medicine, Regensburg \\ University Medical Center, \\ Regensburg, Germany; ${ }^{2}$ Institute \\ of Social and Preventive Medicine, \\ University of Zurich, Zurich, \\ Switzerland
}

Correspondence: Michael F Leitzmann Department of Epidemiology and Preventive Medicine, Regensburg University Medical Center, Franz-Josef-Strauss-Allee II, 93053 Regensburg, Germany Tel +49 94I 9445200

Fax +49 94I 9445202 Email michael.leitzmann@klinik. uni-regensburg.de

\begin{abstract}
At present, only three risk factors for prostate cancer have been firmly established; these are all nonmodifiable: age, race, and a positive family history of prostate cancer. However, numerous modifiable factors have also been implicated in the development of prostate cancer. In the current review, we summarize the epidemiologic data for age, location, and selected behavioral factors in relation to the onset of prostate cancer. Although the available data are not entirely consistent, possible preventative behavioral factors include increased physical activity, intakes of tomatoes, cruciferous vegetables, and soy. Factors that may enhance prostate cancer risk include frequent consumption of dairy products and, possibly, meat. By comparison, alcohol probably exerts no important influence on prostate cancer development. Similarly, dietary supplements are unlikely to protect against the onset of prostate cancer in healthy men. Several factors, such as smoking and obesity, show a weak association with prostate cancer incidence but a positive relation with prostate cancer mortality. Other factors, such as fish intake, also appear to be unassociated with incident prostate cancer but show an inverse relation with fatal prostate cancer. Such heterogeneity in the relationship between behavioral factors and nonadvanced, advanced, or fatal prostate cancers helps shed light on the carcinogenetic process because it discerns the impact of exposure on early and late stages of prostate cancer development. Inconsistent associations between behavioral factors and prostate cancer risk seen in previous studies may in part be due to uncontrolled detection bias because of current widespread use of prostate-specific antigen testing for prostate cancer, and the possibility that certain behavioral factors are systematically related to the likelihood of undergoing screening examinations. In addition, several genes may modify the study results, but data concerning specific gene-environment interactions are currently sparse. Despite large improvements in our understanding of prostate cancer risk factors in the past two decades, present knowledge does not allow definitive recommendations for specific preventative behavioral interventions.
\end{abstract}

Keywords: prostate cancer, risk factors, etiology, epidemiology

\section{Introduction}

Prostate cancer is the most common cancer, excluding nonmelanoma skin cancer, among men in the USA and other industrialized societies. In 2010, it was estimated to account for nearly 220,000 new cancer diagnoses and over 30,000 deaths among US men. ${ }^{1}$ On a global scale, the incidence and mortality of prostate cancer varies widely. ${ }^{2}$ While some of these differences can be attributed to variation in diagnostic intensity, the considerable heterogeneity in prostate cancer mortality across countries indicates that behavioral factors play an important role. The sizeable rise in the incidence and mortality of prostate cancer following migration from low-risk to high-risk countries further supports this hypothesis. ${ }^{3}$ 
There are three nonmodifiable risk factors for prostate cancer: age, race, and a positive family history of prostate cancer. In addition, a number of modifiable or behavioral factors have been found to be associated with prostate cancer risk. While not firmly established, protective behavioral factors may include physical activity and frequent consumption of tomatoes, cruciferous vegetables, and soy foods. In contrast, high dietary intakes of dairy products and meat may increase prostate cancer risk. Several factors, including smoking and obesity, are only weakly related to prostate cancer onset but are positively associated with prostate cancer mortality. By comparison, regular fish consumption shows little association with prostate cancer incidence but may provide protection against fatal prostate cancer. This article provides an overview of the epidemiologic literature regarding these behavioral factors, age, location, and their associations with prostate cancer risk.

\section{Age}

Prostate cancer incidence strongly increases with age. Based on US Surveillance, Epidemiology and End Results Program ${ }^{4}$ statistics from 2000-2008, the incidence rate of prostate cancer is 9.2/100,000 for men aged 40-44 years. That rate increases sharply to $984.8 / 100,000$ in men aged 70-74 years, after which it slightly decreases. ${ }^{4}$ Prostate cancer typically develops slowly and the cancer may be preceded by dysplastic lesions for many years, or even decades. Extrapolations from autopsy studies suggest that most men would have prostate cancer if they lived to be more than 100 years old. ${ }^{5}$ The number of prostate cancers found incidentally at autopsy, which had been asymptomatic and not a cause of death, suggests that small, localized prostate cancers can remain unrecognized for many years before progressing to clinically significant disease. Although the lifetime risk of developing microscopic prostate cancer for a man of 50 years is $42 \%$, the risk of his dying of prostate cancer is only about $3 \% .6,7$

\section{Location}

Incidence rates of prostate cancer tend to be higher in northern and central European countries than in southern and eastern European countries. ${ }^{8}$ In 2008, in Europe as a whole, the incidence rate of prostate cancer was 93.4/100,000, ranging from a low of 27.7 per 100,000 in the Ukraine to a high of 183.1 per 100,000 in Ireland. In the USA, the incidence of prostate cancer is several times higher than in Japan. Also, US rates are 1.6 times higher among African-American men than among Caucasian men. ${ }^{9}$ Studies based on migration patterns show distinct changes in the incidence of prostate cancer.
For example, rates of prostate cancer among Japanese migrants to Hawaii are intermediate between the rates in Japan and those for Caucasians in Hawaii. ${ }^{10}$

During the last two decades, changes have been observed in the incidence rates of prostate cancer in the USA and other industrialized countries, ${ }^{11}$ while prostate cancer mortality has remained relatively stable. In the USA, a strong increase in prostate cancer incidence occurred between 1985 and 1991, followed by a decrease in incidence until 1996. Beginning in 1997, incidence rates have been leveling off. ${ }^{2}$ The rise in incidence rates in the mid-1980s is largely due to an increasingly common use of prostate-specific antigen (PSA) as a method for early detection of prostate cancer. By 2001, 75\% of American men aged 50 years old or older reported that they had undergone a PSA test at least once, ${ }^{12}$ while that statistic is lower in other countries, such as Germany. ${ }^{13}$ The use of PSA testing in the USA to detect prostate cancer in an early phase has shifted the spectrum of diagnosed cancers toward an increased diagnosis of moderately differentiated tumors (Gleason sum scores 5-7). PSA screening is less common in Germany than in the USA, but the procedure has altered the age distribution of prostate cancer cases in Germany as well; the mean age at diagnosis has declined from 73 years of age in 1980 to 69 years in $2006 .{ }^{14}$

\section{Body size}

Epidemiologic studies have generally shown weak positive associations between measures of obesity and total prostate cancer incidence. A meta-analysis of the relation of body mass index (BMI) to prostate cancer included 55,521 cases from 31 cohort studies and 13,232 cases from 25 case-control studies. It yielded a relative risk of total prostate cancer per $5 \mathrm{~kg} / \mathrm{m}^{2}$ increment of BMI of 1.05 (95\% confidence interval $[\mathrm{CI}]=1.01-1.08) .{ }^{15}$ Of note, the positive relation of BMI to prostate cancer was more pronounced for advanced disease (relative risk [RR] per $5 \mathrm{~kg} / \mathrm{m}^{2}$ increment of $\mathrm{BMI}=1.12$; 95\% CI $=1.01-1.23$ ), whereas the association was null for localized disease $\left(\mathrm{RR}\right.$ per $5 \mathrm{~kg} / \mathrm{m}^{2}$ increment of $\mathrm{BMI}=0.96$; $95 \% \mathrm{CI}=0.89-1.03)$. In that meta-analysis, there was little evidence for a relation of central obesity to total prostate cancer, with weakly positive but statistically nonsignificant associations for waist circumference (RR per $10 \mathrm{~cm}$ increment $=1.03 ; 95 \% \mathrm{CI}=0.99-1.07)$ and waist to hip ratio $(\mathrm{RR}$ per 0.1 unit increment $=1.11 ; 95 \% \mathrm{CI}=0.95-1.30$ ).

The greater risk seen for advanced prostate cancer and the lack of an association with obesity for nonadvanced prostate cancer indicates that the biological mechanisms underlying the association between adiposity and prostate 
cancer are complex. The most salient hypotheses relate to the imbalance of various metabolic and hormonal perturbations associated with adiposity. Certain metabolic alterations sustained in obese men, such as increased levels of insulin, insulin-like growth factor-1 (IGF-1), and leptin may increase prostate cancer risk. ${ }^{16,17}$ Other adiposity-related hormonal alterations, such as reduced concentrations of testosterone and higher levels of estrogen may decrease prostate cancer risk. ${ }^{18}$ Further complexity is added by the possibility that testosterone may differentially affect low-grade and highgrade prostate cancers. ${ }^{19}$

\section{Diabetes}

Individuals with type 2 diabetes are characterized by hyperinsulinemia, which may enhance the risk of prostate cancer through the promotion of tumor cell growth. However, numerous epidemiologic studies have shown a decreased risk of prostate cancer among men with diabetes. A recent meta-analysis of 19 studies (published up to 2005) found an inverse association between diabetes and prostate cancer $(\mathrm{RR}=0.84 ; 95 \% \mathrm{CI}=0.76-0.93) .{ }^{20}$

The precise biological mechanisms underlying the relation of diabetes to prostate cancer remain speculative. Hyperinsulinemia is associated with reduced levels of insulin-like growth factor-binding protein (IGFBP) and sex hormone-binding globulin (SHBG) and enhanced levels of circulating IGF-1 and testosterone. ${ }^{21}$ IGF-1 stimulates prostate tumor cell growth ${ }^{22}$ and is related to increased prostate cancer risk. ${ }^{23}$ As diabetes progresses to hypoinsulinemic stages, IGFBP and SHBG levels increase, presumably resulting in less bioavailable IGF-1 and testosterone levels. While available evidence does not indicate a strong association between testosterone levels and prostate cancer, ${ }^{24}$ androgens have been found to induce prostate cancer cell proliferation in vitro, ${ }^{25}$ and low SHBG levels have been related to enhanced prostate cancer risk. ${ }^{18}$ Also, it remains possible that hyperglycemia has a direct adverse impact on the testosterone-synthesizing Leydig cells, adding a further explanation for a potential protective influence of diabetes on risk for prostate cancer.

\section{Physical activity}

Numerous epidemiologic studies have investigated the relationship between physical activity and prostate cancer, and studies have provided both positive and negative associations. A recent meta-analysis of 19 cohort studies and 24 casecontrol studies (published up to 2011) showed a small inverse association between physical activity and prostate cancer. ${ }^{26}$ The combined data from both types of studies yielded a RR of incident prostate cancer of $0.90(95 \%$ $\mathrm{CI}=0.84-0.95)$, when comparing the highest with the lowest levels of total physical activity. A slightly more pronounced prostate cancer risk reduction was observed with occupational activity $(\mathrm{RR}=0.81 ; 95 \% \mathrm{CI}=0.73-0.91)$, whereas the relation with recreational activity was statistically nonsignificant $(\mathrm{RR}=0.95 ; 95 \% \mathrm{CI}=0.89-1.00)$. Studies that considered localized and advanced prostate cancer as distinct disease endpoints revealed no difference in risk estimates. The RR estimates that compared high versus low levels of total physical activity, for localized and advanced prostate cancer were $0.96(95 \% \mathrm{CI}=0.87-1.05)$ and $0.94(95 \% \mathrm{CI}=$

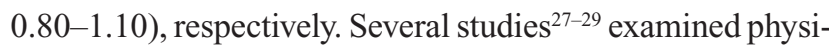
cal activity in relation to prostate cancer mortality and reported a decreased risk of fatal prostate cancer with higher levels of activity, with risk estimates ranging from 0.26 to 0.67 . Thus, increased physical activity is associated with a small reduction in the risk of prostate cancer as a whole, and perhaps a modest to strong decrease in risk of fatal prostate cancer.

Biological pathways that affect whether physical activity potentially prevents prostate cancer include specific growth factors and hormones, such as insulin, IGF-1, and vitamin D. Physical activity boosts insulin sensitivity and reduces insulin levels, ${ }^{30}$ which enhances IGFBP-1 and decreases bioavailable IGF-1. ${ }^{21}$ Physical activity may also favorably affect prostate cancer through higher $25(\mathrm{OH})$ vitamin D levels associated with enhanced outdoor exposure to ultraviolet radiation. ${ }^{31}$ On the other hand, physical activity may decrease prostate cancer risk by augmenting antioxidant defense mechanisms and immune function, ${ }^{32}$ although direct evidence - linking exercise-associated increases in oxidative defense and immunity to lower risk of prostate cancer - is currently unavailable. Physical activity may also decrease prostate cancer risk by preventing chronic low-grade inflammation, a condition that shows a positive association with prostate carcinogenesis. ${ }^{33}$ Physical activity may indirectly influence prostate cancer by preventing obesity, which has been positively related to prostate cancer mortality. ${ }^{34}$ Whether physical activity influences the risk of prostate cancer through a pathway involving a reduction of testosterone concentrations remains speculative. ${ }^{35}$

\section{Aspirin and nonsteroidal anti-inflammatory drugs}

Chronic inflammation is involved in prostate cancer development, and aspirin and other nonsteroidal antiinflammatory drugs (NSAIDs) may play a role in the prevention of prostate cancer by inhibiting the activity of 
cyclo-oxygenases - key enzymes involved in prostaglandin synthesis. A meta-analysis of ten case-control and 14 cohort studies ${ }^{36}$ showed an inverse association between aspirin use and prostate cancer, with a pooled risk estimate comparing users with nonusers of $0.83(95 \% \mathrm{CI}=0.77-0.89)$. By comparison, the relationship between nonaspirin NSAID use and prostate cancer was less pronounced and it did not reach formal statistical significance $(\mathrm{RR}=0.90 ; 95 \% \mathrm{CI}=0.80-1.01)$. A recent nested case-control study ${ }^{37}$ examined different classes of NSAIDs and found that use of propionates (eg, ibuprofen, naproxen) was related to a decreased risk of prostate cancer (odds ratio $[\mathrm{OR}]=0.89 ; 95 \% \mathrm{CI}=0.84-0.95$ ), while use of other classes of NSAIDs was unrelated to risk. Taken together, these data suggest that aspirin and certain classes of nonaspirin NSAIDs may prevent the development of prostate cancer.

\section{Sexual behavior and sexually transmitted diseases}

Several case-control studies reported positive associations between a history of sexually transmitted diseases (STDs), in particular gonorrhea and syphilis, and the risk of prostate cancer. ${ }^{38}$ Most of these studies, however, were retrospective in design and are thus prone to bias. While most prospective studies have shown that a history of gonorrhea or syphilis is not associated with prostate cancer, ${ }^{39-41}$ one recent prospective study ${ }^{41}$ observed an increased risk of prostate cancer in Latino men living in the USA who had a history of gonorrhea $(\mathrm{RR}=1.43 ; 95 \% \mathrm{CI}=1.07-1.91)$. There was a more pronounced risk among foreign-born US-based Latino men $(\mathrm{RR}=1.87 ; 95 \% \mathrm{CI}=1.16-3.02)$ than US-born Latino men $(\mathrm{RR}=1.15 ; 95 \% \mathrm{CI}=0.76-3.02)$. Apart from potential differences in prostate cancer detection rates, it remains possible that the latter group of men had not received timely STD treatment and may thus have experienced a more severe or a longer duration of the infection. Infections of the various types of herpes viruses (including human herpes virus type 8 , herpes simplex viruses 1 and 2, cytomegaly virus, and Epstein-Barr virus) do not appear to increase the risk of prostate cancer. ${ }^{42}$ However, infection with Trichomonas vaginalis was associated with prostate cancer risk in two ${ }^{39,43}$ of three available cohort studies, ${ }^{39,43,44}$ in particular with advanced and fatal prostate cancers. ${ }^{39,43}$ Infection with T. vaginalis is often asymptomatic in men and, if persistent, possibly cause chronic inflammation of the prostate.

Sexual behavior has been thought to be associated with prostate cancer for several reasons. Some factors that might produce this reasoning include an increased likelihood of acquiring an STD, having a high number of sexual partners, and having higher circulating testosterone levels. A meta-analysis (published in 2001) concluded from the data of 12 case-control studies that prostate cancer risk was increased with increasing sexual activity $(\mathrm{OR}=1.2 ; 95 \% \mathrm{CI}=1.1-1.3$, for an increase of three times per week). ${ }^{38}$ More recently, ejaculation frequency was found to be inversely related to prostate cancer risk in a prospective study $(\mathrm{RR}=0.67 ; 95 \% \mathrm{CI}=0.51-0.89$, for $\geq 21$ vs $4-7$ ejaculations per month), which was confined to nonadvanced prostate cancer, while no association was observed for advanced prostate cancer. ${ }^{45}$ Although there is biological plausibility for an inverse association between ejaculation frequency and prostate cancer risk, ie, elimination of chemical carcinogens and toxins from the prostate or alteration of the composition of prostatic fluid through sexual activity, ${ }^{46}$ additional prospective information is required before firm conclusions can be drawn.

\section{Smoking}

Smoking is estimated to cause about $30 \%$ of all cancers worldwide, but smoking has generally not been considered a risk factor for prostate cancer. However, a recent metaanalysis of 24 cohort studies reported a statistically significant increase in prostate cancer risk amongst heavy smokers $(\mathrm{RR}=1.22 ; 95 \% \mathrm{CI}=1.01-1.46$, highest versus lowest cigarettes/day). ${ }^{47}$ In comparison, two studies showed that smoking afforded an apparent protective effect against developing nonadvanced ${ }^{48}$ or low-grade ${ }^{49}$ prostate cancer. Noncausal factors that may explain a potentially decreased risk of nonadvanced prostate cancer among smokers include lower PSA levels in smokers than nonsmokers, ${ }^{50}$ and a lower likelihood that smokers will undergo regular prostate cancer screening examinations compared with nonsmokers.

In contrast to prostate cancer incidence, smoking is positively associated with prostate cancer mortality, with smokers having a $14 \%$ greater risk of dying from prostate cancer than nonsmokers $(95 \% \mathrm{CI}=1.06-1.19) .{ }^{47}$ Smoking may promote the development of more aggressive, hormone-sensitive tumors through numerous mechanisms, including effects on sex steroid hormone levels, mutations in tumor suppressor genes such as p53, and continued exposure to carcinogens such as polycyclic aromatic hydrocarbons contained in cigarette smoke. ${ }^{51}$ 


\section{Dietary factors Fruits and vegetables}

Because of their abundance of vitamins, minerals, and other secondary plant products, frequent consumption of fruits and vegetables has long been thought to decrease cancer incidence and mortality. However, most large cohort studies concluded that there is no strong protective effect of fruit and vegetable consumption on risk of prostate cancer. ${ }^{52-54}$ Notwithstanding this, results from several studies indicate that specific components of fruits and vegetables, such as lycopene, or specific subgroups of fruits and vegetables, for instance, cruciferous vegetables, may be associated with decreased risk of prostate cancer.

\section{Tomatoes and lycopene}

Tomato products are the principal dietary source of bioavailable lycopene in the USA. Lycopene represents the most common carotenoid in human plasma and it is a potent singlet oxygen quencher. ${ }^{55}$ Frequent intake of lycopene or tomatoes has been associated with decreased risk of prostate cancer in numerous prospective and casecontrol studies, and in several serum-based investigations. ${ }^{56}$ However, a considerable number of studies have not been supportive. Thus, there has been intense debate regarding the true relation of lycopene to prostate cancer. Several factors may have contributed to the heterogeneity in results and their interpretations across available studies, including an insufficient contrast between high and low levels of lycopene in studies, lack of repeated measures of lycopene intake, inability of dietary questionnaires to assess key contributors of lycopene (such as tomato sauce), and unaccounted for variation in the bioavailability of lycopene across different food sources. ${ }^{57}$

The most recent available meta-analysis on tomato products and prostate cancer includes ten cohort studies and eleven case-control studies (published up to 2003). ${ }^{58}$ Comparing extreme quintiles of intake, the RR of prostate cancer for intake of raw tomatoes was 0.89 (95\% $\mathrm{CI}=0.80-1.00)$ and for cooked tomatoes $0.81(95 \%$ $\mathrm{CI}=0.71-0.92)$. The major hypothesis concerning a potential benefit of tomato products on prostate cancer risk is that lycopene prevents oxidative DNA damage in prostate tissue by reducing exposure to cellular free radicals.$^{59}$ However, there are other potential mechanisms and additional beneficial compounds in tomatoes, such as other carotenoids and phytochemicals and these may possibly afford protection also.

\section{Cruciferous vegetables}

Cruciferous vegetables represent a group of vegetables that are rich in glucosinolates, which are degraded to biologically active isothiocyanates and indoles. These compounds are thought to exert cancer protective effects by inducing detoxification enzymes such as glutathione-S-transferases (GSTs) and NADPH-quinone oxidoreductase, which are important in the metabolism of carcinogens.

In an analysis of the Health Professionals Follow-up Study, no association between cruciferous vegetables and prostate cancer was found among men who had undergone at least one PSA test in the previous six years ${ }^{60}$ which indicates that detection bias due to screening is important to take into account. However, the Prostate, Lung, Colorectal and Ovarian Cancer Screening Trial, ${ }^{53}$ which was designed to control for prostate cancer screening, observed an inverse association between cruciferous vegetable intake and risk of extraprostatic prostate cancer $(\mathrm{RR}=0.60 ; 95 \% \mathrm{CI}=0.36-0.98$, 1.1 serving vs 0.1 serving/day). The only study thus far to estimate dietary intake of glucosinolates provided evidence for an inverse association with prostate cancer, in particular with low-grade disease. ${ }^{61}$

One possible explanation for the inconsistency concerning the relationship between cruciferous vegetable intake and prostate cancer is genetic heterogeneity in the enzymes that are induced by glucosinolates. Additionally, glucosinolates themselves are products of these enzymes. A nested casecontrol study showed that polymorphisms in NQO1, GSTM1, and GSTT1 modified the association between glucosinolate intake and risk of prostate cancer. ${ }^{62}$ Another study also reported effect modification of the association between broccoli intake and risk of prostate cancer by GSTM1 allele status. ${ }^{63}$ However, the direction of the effect modification differed between those two studies, with an inverse relation among men with deletions of GSTM1 and GSTT1 in the former study, and an inverse relation among GSTM1 positive men in the latter study.

\section{Soy products}

Soy products contain a variety of compounds, in particular isoflavonoids that exert effects on estrogen and testosterone metabolism. There is growing evidence for a beneficial action of isoflavonoids on multiple cancer-related biological pathways, such as carcinogen bioactivation, cell-signaling, cell cycle regulation, angiogenesis, oxidative stress, and chronic inflammation. ${ }^{64}$ It has been speculated that the incidence of prostate cancer in Eastern Asia is lower than in 
Western societies because of the high soy consumption in Asia. In a meta-analysis including five cohort and nine casecontrol studies, total consumption of soy foods $(\mathrm{OR}=0.74$; 95\% CI 0.63-0.89, for high vs low consumption) and nonfermented soy foods $(\mathrm{OR}=0.70 ; 95 \% \mathrm{CI}=0.56-0.88)$ were inversely associated with prostate cancer risk. ${ }^{65}$ However, in that meta-analysis the inverse association between soy food consumption and prostate cancer risk was confined to Asian men, whereas no association was seen among studies on men from Western societies. ${ }^{65}$ Possible explanations for this observation include different types of soy foods consumed in Asian and Western countries, or that the low consumption of soy food in Western countries fails to reach the threshold needed to produce an inverse association with prostate cancer.

\section{Fish}

Fish is rich in polyunsaturated fatty acids such as eicosapentaenoic acid (20:5n-3) and docosahexaenoic acid (22:6n-3), which have anti-inflammatory properties and have been linked to decreased prostate cancer risk in laboratory settings. ${ }^{66}$ Fatty acids are involved in the regulation of prostaglandin production via the cyclo-oxygenase and lipoxygenase pathways, which play an important role in inflammation, proliferation, and angiogenesis. However, epidemiologic data in support of a protective relationship between fish intake and prostate cancer incidence has been limited. The most comprehensive evidence to date comes from a recent meta-analysis of fish consumption and prostate cancer. ${ }^{67}$ That investigation encompassed data from 12 case-control studies including 5777 prostate cancer cases and 12 cohort studies including 13,924 prostate cancer cases. Comparing extreme quantiles of fish intake, analyses suggested a small decrease in risk of prostate cancer incidence from the case-control studies, with a pooled OR of $0.85(95 \% \mathrm{CI}=0.72-1.00)$. Findings for the cohort studies were largely null, with a pooled RR for prostate cancer incidence of 1.01 (95\% CI $=0.90-1.14)$. However, a strong risk reduction with frequent fish intake was noted for prostate cancer mortality, based on the results of four cohort studies. As compared to infrequent fish consumption (less than twice per month), eating fish more than three times per week was associated with a RR for prostate cancer mortality of $0.37(95 \% \mathrm{CI}=0.18-0.74)$. The findings of a weak or null relationship between fish intake and overall prostate cancer incidence, and a strong inverse association between fish consumption and fatal prostate cancer suggest that the antiinflammatory properties of fish are specific to the prevention of aggressive, clinically relevant prostate cancers.

\section{Meat}

Meat is a rich source of several micronutrients such as $\mathrm{B}$ vitamins and iron. However, meat is also rich in saturated fats and cholesterol. In ecological studies, high meat consumption has been found to be correlated with increased cancer incidence. ${ }^{68} \mathrm{~A}$ recent meta-analysis of 15 prospective studies did not observe an association between red meat consumption and risk of total $(\mathrm{RR}=1.00 ; 95 \% \mathrm{CI}=0.96-1.05$ per $100 \mathrm{~g}$ increment $)$ or advanced prostate cancer $(\mathrm{RR}=0.97$; 95\% CI $=0.91-1.02$ ). Similarly, there was no association between processed meat consumption and risk of total prostate cancer $(\mathrm{RR}=1.02 ; 95 \% \mathrm{CI}=1.00-1.04$ per $30 \mathrm{~g}$ increment). ${ }^{6}$

It has been speculated that it is not meat consumption per se but, in particular, meat prepared by grilling, barbecuing, and frying that leads to the formation of polycyclic aromatic hydrocarbons and heterocyclic amines (HCA) that may increase the risk of prostate cancer. For example, a positive association between the intake of 2-amino-1-methyl-6phenylimidazo[4,5-b]pyridine (PhIP) and prostate cancer was seen in the Prostate, Lung, Colorectal and Ovarian Cancer Screening Trial, in particular, with advanced disease. ${ }^{70} \mathrm{HCAs}$ are metabolized in the human body and may eventually form HCA-DNA adducts, which are thought to cause structural damage to DNA. ${ }^{71}$ In a group of 268 US men, grilled meat, in particular, red meat, was positively correlated with PhIPDNA adducts in prostate tumor cells, whereas the correlation with adducts in noncancerous cells was less pronounced. ${ }^{71}$

\section{Dairy products}

Dairy products are an abundant source of protein, calcium, and several B vitamins such as riboflavin. On the other hand, they are also rich in saturated fats, which have been shown to be positively associated with some cancers. ${ }^{68} \mathrm{~A}$ high consumption of dairy products has been associated with an increased prostate cancer risk in several, but not all, studies. A meta-analysis (including studies published up to 2006) revealed a positive association between dairy consumption and prostate cancer risk $(\mathrm{RR}=1.13 ; 95 \% \mathrm{CI}=1.02-1.24$, highest vs lowest quantile). ${ }^{72}$

The positive relationship between dairy consumption and prostate cancer seen in several studies led to the hypothesis that the causal factor may be calcium. Based on the observation that calcium intake is positively correlated with circulating levels of IGF- $1,{ }^{73}$ one potential biological mechanism linking calcium to prostate cancer risk is the IGF-1 axis. A further possible mechanism involves the suppression of 1,25-dihydroxyvitamin $\mathrm{D}_{3}$ production by calcium. ${ }^{74}$ 
In a meta-analysis based on ten prospective studies, men with the highest intake of calcium $(\mathrm{RR}=1.39 ; 95 \% \mathrm{CI}=1.09-1.77)$ were more likely to develop prostate cancer than men with the lowest intake. ${ }^{75}$ However, not all studies show a clear association between calcium intake and prostate cancer risk. One possible explanation for these varying results is an insufficient contrast between high and low calcium intakes in study populations. In addition, positive associations with prostate cancer, particularly with advanced disease, have been limited to studies that included assessments of very high calcium intakes of $2000 \mathrm{mg} /$ day or more, an intake that is achievable only with supplemental calcium. ${ }^{76,77}$ However, the association between calcium supplement use and prostate cancer risk is not consistent in all studies. ${ }^{78}$ Thus, the relation of calcium supplement use to prostate cancer risk remains inconclusive.

\section{Alcohol}

The first metabolite of alcohol, acetaldehyde, is a potent carcinogen, and alcohol consumption is considered to be a risk factor for many cancers. ${ }^{68}$ In a meta-analysis of 50 case-control and 22 cohort studies (published up to $2010),{ }^{79}$ the relative risk for any alcohol drinking compared with non/occasional drinking was 1.06 (95\% CI = 1.01-1.10). In the European Prospective Investigation into Cancer and Nutrition cohort, alcohol consumption was not associated with prostate cancer risk, irrespective of beverage type and stage and grade of disease.$^{80} \mathrm{By}$ comparison, the National Institutes of Health-American Association of Retired Persons Diet and Health Study reported that consumption of $6+$ alcoholic drinks/day was related to an increased risk of nonadvanced prostate cancer $(\mathrm{RR}=1.25 ; 95 \% \mathrm{CI}=1.13-1.37)$, but there was no association with advanced disease and an inverse association with fatal prostate cancer. ${ }^{81}$ In the Health Professionals Follow-up Study, alcohol consumption was not associated with prostate cancer in the overall analysis but there was an increased risk of prostate cancer in men with bingedrinking behavior. ${ }^{82}$ As prostate cancer possibly develops over many decades, it may be long-term drinking habits that are related to prostate cancer risk rather than drinking behavior close to diagnosis.

\section{Tea and coffee}

Several prospective studies found no statistically significant relations of coffee intake to prostate cancer. ${ }^{83-86}$ In contrast, a recent US cohort study ${ }^{87}$ reported an inverse association between high coffee consumption (6+ cups/day) and risk of prostate cancer $(\mathrm{RR}=0.82 ; 95 \% \mathrm{CI}=0.68-0.98)$. When considering advanced and nonadvanced prostate cancers as separate endpoints, a strong inverse risk estimate emerged for advanced cancer $(\mathrm{RR}=0.47 ; 95 \% \mathrm{CI}=0.28-0.77)$, whereas no relation remained for nonadvanced cancer $(\mathrm{RR}=0.93$; $95 \% \mathrm{CI}=0.74-1.16$ ). The authors of that study ${ }^{87}$ hypothesized that the biological mechanisms through which frequent coffee consumption protects against advanced prostate cancer involve antioxidant, anti-inflammatory, or insulin-sensitizing activities of the numerous beneficial components contained in coffee, including lignans, phytoestrogens, and chlorogenic acids.

With respect to tea consumption, a recent meta-analysis ${ }^{88}$ reported an inverse association between green tea consumption and prostate cancer risk, which was confined to case-control studies. The authors did not find an association with black tea consumption. Intriguingly, results of a small, randomized, controlled trial suggest that green tea catechins inhibit the progression of high-grade prostate intraepithelial neoplasia to prostate cancer. ${ }^{89}$ Thus far, however, epidemiologic evidence regarding tea intake in relation to prostate cancer is largely confined to Asian men, who consume higher amounts of green tea than US or European men.

\section{Dietary patterns}

Dietary pattern analysis aims at integrating different aspects of the diet instead of analyzing the effects of single dietary components. Prospective studies have generally not identified specific dietary patterns associated with prostate cancer. ${ }^{90,91}$ One exception is a cohort study that linked a Southern dietary pattern to decreased prostate cancer risk. ${ }^{92}$ The authors of that study, however, speculated that the observed inverse association was not explained by a Southern diet itself but rather, by a Southern lifestyle in general, which includes frequent sun exposure with enhanced vitamin D levels. Several case-control studies ${ }^{93-95}$ reported a positive association between a Western dietary pattern and prostate cancer, but the possibility of recall bias in those studies cannot be excluded as an explanation for the results. Thus, the relation of dietary patterns to prostate cancer remains unclear.

\section{Dietary supplements}

In a representative study in the USA, more than $50 \%$ of participants reported taking dietary supplements. ${ }^{96}$ Because of real or acclaimed beneficial effects of several dietary components present in dietary supplements, such as vitamins and minerals, dietary supplements are commonly used 
to prevent chronic diseases, including cancer. The relation of dietary supplement use to prostate cancer risk has been examined in several studies, but the results from these investigations are heterogeneous, which is in part due to the wealth of dietary supplements used in the populations under study. Both the Cancer Prevention Study II and the National Institutes of Health-American Association of Retired Persons Diet and Health Study showed an increased risk of fatal prostate cancer among multivitamin users compared with nonusers. ${ }^{97,98}$ In the Carotene and Retinol Efficacy Trial study, there was no association between supplement use and risk of prostate cancer. ${ }^{99}$ However, men who were in the Carotene and Retinol Efficacy Trial intervention arm (beta-carotene plus retinyl palmitate) and additionally used other supplements had an increased risk of aggressive prostate cancer. This association disappeared after discontinuation of the study supplements and the authors speculated that the effects of antioxidants on cellular processes may vary depending on the oxidative milieu of the tissue. In contrast, the AlphaTocopherol, Beta-Carotene Cancer Prevention Study, which focused on Finnish elderly male smokers, found that supplementation of alpha-tocopherol $(50 \mathrm{mg} / \mathrm{d})$ was significantly associated with decreased prostate cancer risk. ${ }^{100}$ However, in the Selenium and Vitamin E Cancer Prevention Trial trial of over 35,000 men, which was designed to examine the effect of vitamin $E$ and/or selenium supplementation on prostate cancer risk in healthy men, neither vitamin E nor selenium supplementation was significantly associated with prostate cancer risk. $^{101}$

\section{Challenges and future directions}

The current review of the literature suggests that several behavioral factors are associated with the risk of prostate cancer. However, important questions remain to be addressed in future investigations. The spectrum of prostate cancer cases included in epidemiologic studies has changed considerably over time. Studies conducted before the introduction of testing for elevated PSA contained a high proportion of prostate cancers that were diagnosed at later stages, whereas more recent studies comprise a large number of cases that are characterized by early lesions and lower tumor stages. As a consequence, exposures that play a prominent role in the early stages of prostate cancer development are still detectable as risk factors in current studies, while it has become increasingly challenging for current studies to detect risk factors for prostate cancer that play a role late in the carcinogenetic process. Larger studies may help solve the problem of low numbers of advanced and fatal prostate cancer cases in contemporary studies by creating cohort consortia. Furthermore, some men are more likely to undergo PSA screening examinations than others, and the likelihood of attending prostate cancer screening tests may systematically track with certain lifestyle and dietary factors. Thus, a careful assessment of screening visits and their results is crucial to address potential detection bias in ongoing and future prostate cancer studies.

Men diagnosed with prostate cancer have a good survival rate if the cancer is detected early. With better treatment options, epidemiologic research should not only focus on risk factors for prostate cancer incidence, but also prostate cancer mortality. Smoking is a good example of a behavioral factor that increases risk for prostate cancer mortality more strongly than prostate cancer incidence. Thus, further research that focuses on differences in associations with incident prostate cancer and fatal prostate cancer is warranted.

An additional reason for inconsistencies of results in prostate cancer studies is the likely differences that occur in the genes that regulate the metabolism of nutrients or carcinogens, as well as those that regulate the metabolism of sex steroid hormones and growth factors. So far, only a few studies have addressed whether genetic variants modify relations of dietary, behavioral, or hormonal factors to prostate cancer risk. Data pooling will be necessary to examine these interactions as they usually require a very large number of study participants for adequate statistical power. Such collaborative work should help further clarify the etiology of this important disease.

\section{Disclosure}

The authors declare that they have no conflicts of interest in this work.

\section{References}

1. Jemal A, Siegel R, Xu J, Ward E. Cancer statistics, 2010. CA Cancer J Clin. 2010;60(5):277-300.

2. Jemal A, Bray F, Center MM, Ferlay J, Ward E, Forman D. Global cancer statistics. CA Cancer J Clin. 2011;61(2):69-90.

3. Haenszel W, Kurihara M. Studies of Japanese migrants. I. Mortality from cancer and other diseases among Japanese in the United States. J Natl Cancer Inst. 1968;40(1):43-68.

4. Surveillance, Epidemiology, and End Results Program (SEER) of the National Cancer Institute. Fast Stats: An interactive tool for access to SEER cancer statistics. Bethesda, MD: SEER, National Cancer Institute; nd. Available from: www.seer.cancer.gov/faststats. Accessed November $11,2011$.

5. Gronberg H. Prostate cancer epidemiology. Lancet. 2003;361(9360): 859-864.

6. Frankel S, Smith GD, Donovan J, Neal D. Screening for prostate cancer. Lancet. 2003;361(9363):1122-1128. 
7. Etzioni R, Penson DF, Legler JM, et al. Overdiagnosis due to prostate-specific antigen screening: lessons from U.S. prostate cancer incidence trends. J Natl Cancer Inst. 2002;94(13):981-990.

8. Ferlay J, Parkin DM, Steliarova-Foucher E. Estimates of cancer incidence and mortality in Europe in 2008. Eur J Cancer. 2010;46(4): 765-781.

9. Ferlay J, Bray F, Pisani P, Parkin D. GLOBOCAN 2002: Cancer Incidence, Mortality and Prevalence Worldwide. IARC CancerBase No. 5. version 2.0 ed. Lyon: IARCPress; 2004.

10. Kolonel LN, Altshuler D, Henderson BE. The multiethnic cohort study: exploring genes, lifestyle and cancer risk. Nat Rev Cancer. 2004;4(7):519-527.

11. Hsing AW, Tsao L, Devesa SS. International trends and patterns of prostate cancer incidence and mortality. Int J Cancer. 2000;85(1): 60-67.

12. Sirovich BE, Schwartz LM, Woloshin S. Screening men for prostate and colorectal cancer in the United States: does practice reflect the evidence? JAMA. 2003;289(11):1414-1420

13. Sieverding M, Matterne U, Ciccarello L, Luboldt HJ. Early detection of prostate cancer in Germany. A study of a representative random sample of the population. Urologe A. 2008;47(9):1233-1238.

14. Robert-Koch-Institut. Krebs in Deutschland 2003 - 2004. Häufigkeiten und Trends. Vol. 6. überarbeitete Auflage. Berlin 2008.

15. MacInnis RJ, English DR. Body size and composition and prostate cancer risk: systematic review and meta-regression analysis. Cancer Causes Control. 2006;17(8):989-1003.

16. Hsing AW, Chua S Jr, Gao YT, et al. Prostate cancer risk and serum levels of insulin and leptin: a population-based study. J Natl Cancer Inst. 2001;93(10):783-789.

17. Chang S, Hursting SD, Contois JH, et al. Leptin and prostate cancer. Prostate. 2001;46(1):62-67.

18. Gann PH, Hennekens CH, Ma J, Longcope C, Stampfer MJ. Prospective study of sex hormone levels and risk of prostate cancer. J Natl Cancer Inst. 1996;88(16):1118-1126.

19. Thompson IM, Goodman PJ, Tangen CM, et al. The influence of finasteride on the development of prostate cancer. $N$ Engl J Med. 2003;349(3):215-224.

20. Kasper JS, Giovannucci E. A meta-analysis of diabetes mellitus and the risk of prostate cancer. Cancer Epidemiol Biomarkers Prev. 2006;15(11):2056-2062.

21. Giovannucci E. Nutrition, insulin, insulin-like growth factors and cancer. Horm Metab Res. 2003;35(11-12):694-704.

22. Iwamura M, Sluss PM, Casamento JB, Cockett AT. Insulin-like growth factor I: action and receptor characterization in human prostate cancer cell lines. Prostate. 1993;22(3):243-252.

23. Chan JM, Stampfer MJ, Giovannucci E, et al. Plasma insulinlike growth factor-I and prostate cancer risk: a prospective study. Science.1998;279(5350):563-566.

24. Roddam AW, Allen NE, Appleby P, Key TJ. Endogenous sex hormones and prostate cancer: a collaborative analysis of 18 prospective studies. J Natl Cancer Inst. 2008;100(3):170-183.

25. Webber MM, Bello D, Kleinman HK, Wartinger DD, Williams DE, Rhim JS. Prostate specific antigen and androgen receptor induction and characterization of an immortalized adult human prostatic epithelial cell line. Carcinogenesis. 1996;17(8):1641-1646.

26. Liu Y, Hu F, Li D, et al. Does physical activity reduce the risk of prostate cancer? A systematic review and meta-analysis. Eur Urol. 2011;60(5):1029-1044.

27. Giovannucci EL, Liu Y, Leitzmann MF, Stampfer MJ, Willett WC. A prospective study of physical activity and incident and fatal prostate cancer. Arch Intern Med. 2005;165(9):1005-1010.

28. Nilsen TI, Romundstad PR, Vatten LJ. Recreational physical activity and risk of prostate cancer: a prospective population-based study in Norway (the HUNT study). Int J Cancer. 2006;119(12):2943-2947.

29. Paffenbarger RS Jr, Hyde RT, Wing AL. Physical activity and incidence of cancer in diverse populations: a preliminary report. Am J Clin Nutr. 1987;45(1 Suppl):312-317.
30. Devlin JT. Effects of exercise on insulin sensitivity in humans. Diabetes Care. 1992;15(11):1690-1693.

31. Giovannucci E, Liu Y, Rimm EB, et al. Prospective study of predictors of vitamin D status and cancer incidence and mortality in men. $J$ Natl Cancer Inst. 2006;98(7):451-459.

32. Romeo J, Warnberg J, Pozo T, Marcos A. Physical activity, immunity and infection. Proc Nutr Soc. 2010;69(3):390-399.

33. De Marzo AM, Platz EA, Sutcliffe S, et al. Inflammation in prostate carcinogenesis. Nat Rev Cancer. 2007;7(4):256-269.

34. Wright ME, Chang SC, Schatzkin A, et al. Prospective study of adiposity and weight change in relation to prostate cancer incidence and mortality. Cancer. 2007;109(4):675-684.

35. McTiernan A. Mechanisms linking physical activity with cancer. Nat Rev Cancer. 2008;8(3):205-211.

36. Mahmud SM, Franco EL, Aprikian AG. Use of nonsteroidal antiinflammatory drugs and prostate cancer risk: a meta-analysis. Int $J$ Cancer. 2010;127(7):1680-1691.

37. Mahmud SM, Franco EL, Turner D, et al. Use of non-steroidal antiinflammatory drugs and prostate cancer risk: a population-based nested case-control study. PLoS One. 2011;6(1):e16412.

38. Dennis LK, Dawson DV. Meta-analysis of measures of sexual activity and prostate cancer. Epidemiology. 2002;13(1):72-79.

39. Sutcliffe S, Giovannucci E, De Marzo AM, Leitzmann MF, Willett WC, Platz EA. Gonorrhea, syphilis, clinical prostatitis, and the risk of prostate cancer. Cancer Epidemiol Biomarkers Prev. 2006;15(11): 2160-2166.

40. Huang WY, Hayes R, Pfeiffer R, et al. Sexually transmissible infections and prostate cancer risk. Cancer Epidemiol Biomarkers Prev. 2008;17(9):2374-2381.

41. Cheng I, Witte JS, Jacobsen SJ, et al. Prostatitis, sexually transmitted diseases, and prostate cancer: the California Men's Health Study. PLoS One. 2010;5(1):e8736.

42. Sutcliffe S. Sexually transmitted infections and risk of prostate cancer: review of historical and emerging hypotheses. Future Oncol. 2010;6(8): 1289-1311.

43. Stark JR, Judson G, Alderete JF, et al. Prospective study of Trichomonas vaginalis infection and prostate cancer incidence and mortality: Physicians' Health Study. J Natl Cancer Inst. 2009;101(20): 1406-1411.

44. Sutcliffe S, Alderete JF, Till C, et al. Trichomonosis and subsequent risk of prostate cancer in the Prostate Cancer Prevention Trial. Int J Cancer. 2009;124(9):2082-2087.

45. Leitzmann MF, Platz EA, Stampfer MJ, Willett WC, Giovannucci E. Ejaculation frequency and subsequent risk of prostate cancer. JAMA 2004;291(13):1578-1586.

46. Pichini S, Zuccaro P, Pacifici R. Drugs in semen. Clin Pharmacokinet. 1994;26(5):356-373.

47. Huncharek M, Haddock KS, Reid R, Kupelnick B. Smoking as a risk factor for prostate cancer: a meta-analysis of 24 prospective cohort studies. Am J Public Health. 2010;100(4):693-701.

48. Watters JL, Park Y, Hollenbeck A, Schatzkin A, Albanes D. Cigarette smoking and prostate cancer in a prospective US cohort study. Cancer Epidemiol Biomarkers Prev. 2009;18(9):2427-2435.

49. Giovannucci E, Liu Y, Platz EA, Stampfer MJ, Willett WC. Risk factors for prostate cancer incidence and progression in the health professionals follow-up study. Int J Cancer. 2007;121(7):1571-1578.

50. Singer EA, Palapattu GS, van Wijngaarden E. Prostate-specific antigen levels in relation to consumption of nonsteroidal anti-inflammatory drugs and acetaminophen. Cancer. 2008;113(8):2053-2057.

51. Zu K, Giovannucci E. Smoking and aggressive prostate cancer: a review of the epidemiologic evidence. Cancer Causes Control. 2009;20(10): 1799-1810.

52. Key TJ. Fruit and vegetables and cancer risk. Br J Cancer. 2011;104(1): 6-11.

53. Kirsh VA, Peters U, Mayne ST, et al. Prospective study of fruit and vegetable intake and risk of prostate cancer. J Natl Cancer Inst. 2007; 99(15):1200-1209. 
54. Takachi R, Inoue M, Sawada N, et al. Fruits and vegetables in relation to prostate cancer in Japanese men: the Japan Public Health Center-Based Prospective Study. Nutr Cancer. 2010;62(1):30-39.

55. Kaplan LA, Lau JM, Stein EA. Carotenoid composition, concentrations, and relationships in various human organs. Clin Physiol Biochem. 1990;8(1):1-10.

56. Miller EC, Giovannucci E, Erdman JW Jr, Bahnson R, Schwartz SJ, Clinton SK. Tomato products, lycopene, and prostate cancer risk. Urol Clin North Am. 2002;29(1):83-93.

57. Giovannucci E, Rimm EB, Liu Y, Stampfer MJ, Willett WC. A prospective study of tomato products, lycopene, and prostate cancer risk. J Natl Cancer Inst. 2002;94(5):391-398.

58. Etminan M, Takkouche B, Caamano-Isorna F. The role of tomato products and lycopene in the prevention of prostate cancer: a metaanalysis of observational studies. Cancer Epidemiol Biomarkers Prev. 2004;13(3):340-345.

59. Chen L, Stacewicz-Sapuntzakis M, Duncan C, et al. Oxidative DNA damage in prostate cancer patients consuming tomato sauce-based entrees as a whole-food intervention. J Natl Cancer Inst. 2001;93(24): $1872-1879$

60. Giovannucci E, Rimm EB, Liu Y, Stampfer MJ, Willett WC. A prospective study of cruciferous vegetables and prostate cancer. Cancer Epidemiol Biomarkers Prev. 2003;12(12):1403-1409.

61. Steinbrecher A, Linseisen J. Dietary intake of individual glucosinolates in participants of the EPIC-Heidelberg cohort study. Ann Nutr Metab. 2009;54(2):87-96.

62. Steinbrecher A, Rohrmann S, Timofeeva M, Risch A, Jansen En, Linseisen J. Dietary glucosinolate intake, polymorphisms in selected biotransformation enzymes, and risk of prostate cancer. Cancer Epidemiol Biom Prev. 2010;19(1):135-143.

63. Joseph MA, Moysich KB, Freudenheim JL, et al. Cruciferous vegetables, genetic polymorphisms in glutathione S-transferases M1 and T1, and prostate cancer risk. Nutr Cancer. 2004;50(2):206-213.

64. Jian L. Soy, isoflavones, and prostate cancer. Mol Nutr Food Res. 2009; 53(2):217-226.

65. Yan L, Spitznagel EL. Soy consumption and prostate cancer risk in men: a revisit of a meta-analysis. Am J Clin Nutr. 2009;89(4):1155-1163.

66. Rose DP, Connolly JM. Omega-3 fatty acids as cancer chemopreventive agents. Pharmacol Ther. 1999;83(3):217-244.

67. Szymanski KM, Wheeler DC, Mucci LA. Fish consumption and prostate cancer risk: a review and meta-analysis. Am J Clin Nutr. 2010;92(5): 1223-1233.

68. American Institute for Cancer Research (AICR)/World Cancer Research Fund. Food, Nutrition, Physical Activity, and the Prevention of Cancer: a Global Perspective. Washington, DC: AICR; 2007.

69. Alexander DD, Mink PJ, Cushing CA, Sceurman B. A review and meta-analysis of prospective studies of red and processed meat intake and prostate cancer. Nutr J. 2010;9:50.

70. Cross AJ, Peters U, Kirsh VA, et al. A prospective study of meat and meat mutagens and prostate cancer risk. Cancer Res. 2005;65(24): 11779-11784

71. Tang D, Liu JJ, Rundle A, et al. Grilled meat consumption and PhIPDNA adducts in prostate carcinogenesis. Cancer Epidemiol Biomarkers Prev. 2007;16(4):803-808.

72. Qin LQ, Xu JY, Wang PY, Tong J, Hoshi K. Milk consumption is a risk factor for prostate cancer in Western countries: evidence from cohort studies. Asia Pac J Clin Nutr. 2007;16(3):467-476.

73. Holmes MD, Pollak MN, Willett WC, Hankinson SE. Dietary correlates of plasma insulin-like growth factor I and insulin-like growth factor binding protein 3 concentrations. Cancer Epidemiol Biomarkers Prev. 2002;11(9):852-861.

74. Giovannucci E. Dietary influences of $1,25(\mathrm{OH}) 2$ vitamin D in relation to prostate cancer: a hypothesis. Cancer Causes Control. 1998;9(6): 567-582.

75. Gao X, LaValley MP, Tucker KL. Prospective studies of dairy product and calcium intakes and prostate cancer risk: a meta-analysis. J Natl Cancer Inst. 2005;97(23):1768-1777.
76. Giovannucci E, Rimm EB, Wolk A, et al. Calcium and fructose intake in relation to risk of prostate cancer. Cancer Res. 1998;58(3): $442-447$.

77. Rodriguez C, McCullough ML, Mondul AM, et al. Calcium, dairy products, and risk of prostate cancer in a prospective cohort of United States men. Cancer Epidemiol Biomarkers Prev. 2003;12(7): 597-603.

78. Park Y, Mitrou PN, Kipnis V, Hollenbeck A, Schatzkin A, Leitzmann MF. Calcium, dairy foods, and risk of incident and fatal prostate cancer: the NIH-AARP Diet and Health Study. Am J Epidemiol. 2007;166(11):1270-1279.

79. Rota M, Scotti L, Turati F, et al. Alcohol consumption and prostate cancer risk: a meta-analysis of the dose-response relation. Eur J Cancer Prev. 2011. Epub ahead of print.

80. Rohrmann S, Linseisen J, Key TJ, et al. Alcohol consumption and the risk for prostate cancer in the European Prospective Investigation into Cancer and Nutrition. Cancer Epidemiol Biomarkers Prev. 2008;17(5):1282-1287.

81. Watters JL, Park Y, Hollenbeck A, Schatzkin A, Albanes D. Alcoholic beverages and prostate cancer in a prospective US cohort study. Am J Epidemiol. 2010;172(7):773-780.

82. Platz EA, Leitzmann MF, Rimm EB, Willett WC, Giovannucci E. Alcohol intake, drinking patterns, and risk of prostate cancer in a large prospective cohort study. Am J Epidemiol. 2004;159(5):444-453.

83. Nomura A, Heilbrun LK, Stemmermann GN. Prospective study of coffee consumption and the risk of cancer. J Natl Cancer Inst. 1986; 76(4):587-590.

84. Severson RK, Nomura AM, Grove JS, Stemmermann GN. A prospective study of demographics, diet, and prostate cancer among men of Japanese ancestry in Hawaii. Cancer Res.1989;49(7):1857-1860.

85. Le Marchand L, Kolonel LN, Wilkens LR, Myers BC, Hirohata T, Animal fat consumption and prostate cancer: a prospective study in Hawaii. Epidemiology. 1994;5(3):276-282.

86. Jacobsen BK, Bjelke E, Kvale G, Heuch I. Coffee drinking, mortality, and cancer incidence: results from a Norwegian prospective study. J Natl Cancer Inst. 1986;76(5):823-831.

87. Wilson KM, Kasperzyk JL, Rider JR, et al. Coffee consumption and prostate cancer risk and progression in the Health Professionals Follow-up Study. J Natl Cancer Inst. 2011;103(11):876-884.

88. Zheng J, Yang B, Huang T, Yu Y, Yang J, Li D. Green tea and black tea consumption and prostate cancer risk: an exploratory meta-analysis of observational studies. Nutr Cancer. 2011;63(5):663-672.

89. Bettuzzi S, Brausi M, Rizzi F, Castagnetti G, Peracchia G, Corti A. Chemoprevention of human prostate cancer by oral administration of green tea catechins in volunteers with high-grade prostate intraepithelial neoplasia: a preliminary report from a one-year proof-of-principle study. Cancer Res. 2006;66(2):1234-1240.

90. Wu K, Hu FB, Willett WC, Giovannucci E. Dietary patterns and risk of prostate cancer in US men. Cancer Epidemiol Biomarkers Prev. 2006;15(1):167-171.

91. Muller DC, Severi G, Baglietto L, et al. Dietary patterns and prostate cancer risk. Cancer Epidemiol Biomarkers Prev. 2009;18(11): 3126-3129.

92. Tseng M, Breslow RA, DeVellis RF, Ziegler RG. Dietary patterns and prostate cancer risk in the National Health and Nutrition Examination Survey Epidemiological Follow-up Study cohort. Cancer Epidemiol Biomarkers Prev. 2004;13(1):71-77.

93. De Stefani E, Ronco AL, Deneo-Pellegrini H, et al. Dietary patterns and risk of advanced prostate cancer: a principal component analysis in Uruguay. Cancer Causes Control. 2010;21(7):1009-1016.

94. Ambrosini GL, Fritschi L, de Klerk NH, Mackerras D, Leavy J. Dietary patterns identified using factor analysis and prostate cancer risk: a case control study in Western Australia. Ann Epidemiol. 2008;18(5):364-370.

95. Walker M, Aronson KJ, King W, et al. Dietary patterns and risk of prostate cancer in Ontario, Canada. Int J Cancer. 2005;116(4): $592-598$. 
96. Radimer K, Bindewald B, Hughes J, Ervin B, Swanson C, Picciano MF. Dietary supplement use by US adults: data from the National Health and Nutrition Examination Survey, 1999-2000. Am J Epidemiol. 2004; 160(4):339-349.

97. Stevens VL, McCullough ML, Diver WR, et al. Use of multivitamins and prostate cancer mortality in a large cohort of US men. Cancer Causes and Control. 2005;16(6):643-650.

98. Lawson KA, Wright ME, Subar A, et al. Multivitamin use and risk of prostate cancer in the National Institute of Health-AARP Diet and Health Study. J Natl Cancer Inst. 2007;99(10):754-764.

99. Neuhouser ML, Barnett MJ, Kristal AR, et al. Dietary supplement use and prostate cancer risk in the Carotene and Retinol Efficacy Trial. Cancer Epidemiol Biomarkers Prev. 2009;18(8):2202-2206.
100. Heinonen O, Albanes D, Virtamo J, et al. Prostate cancer and supplementation with alpha-tocopherol and beta-carotene: incidence and mortality in a controlled trial. J Natl Cancer Inst. 1998;90(6): 440-446.

101. Lippman SM, Klein EA, Goodman PJ, et al. Effect of selenium and vitamin $\mathrm{E}$ on risk of prostate cancer and other cancers: the Selenium and Vitamin E Cancer Prevention Trial (SELECT). JAMA 2009;301(1):39-51.
Clinical Epidemiology

\section{Publish your work in this journal}

Clinical Epidemiology is an international, peer-reviewed, open access journal focusing on disease and drug epidemiology, identification of risk factors and screening procedures to develop optimal preventative initiatives and programs. Specific topics include: diagnosis, prognosis, treatment, screening, prevention, risk factor modification, systematic

\section{Dovepress}

reviews, risk \& safety of medical interventions, epidemiology \& biostatical methods, evaluation of guidelines, translational medicine, health policies \& economic evaluations. The manuscript management system is completely online and includes a very quick and fair peer-review system, which is all easy to use. 